\title{
Childhood Obesity: The Indian Scenario Compared with World Wide
}

\author{
Michael Anjello Jothi Rajan ${ }^{1 *}$, R Srinivasan ${ }^{1}$ and Arockiam Thaddeus ${ }^{2}$ \\ ${ }^{1}$ Tamil Nadu State Council for Science and Technology, India
}

${ }^{2} J a y a r a j$ Annapackiam College for Women, Periyakulam, India

Submission: January 16, 2018; Published: February 08, 2018

*Corresponding author: Michael Anjello Jothi Rajan, Tamil Nadu State Council for Science and Technology, India, Email: anjellojothi@gmail.com

Abstract

In this small review article the authors present the childhood obesity in India as on today. This might make the reader think that India is a Developed Nation, but rather it is a Developing Nation. Obesity is the sign of rich people in India. On one side we see Obessed children and on the other side we see mal-nutritioned children. The authors try to analyze this problem in the Indian point of view and throw some light on reducing obesity.

\section{Introduction}

\section{Defining childhood obesity}

Body mass index (BMI) is a measure used to determine childhood overweight and obesity. Overweight is defined as a BMI at or above the $85^{\text {th }}$ percentile and below the $95^{\text {th }}$ percentile for children and teens of the same age and sex. Obesity is defined as a BMI at or above the $95^{\text {th }}$ percentile for children and teens of the same age and sex.

BMI is calculated by dividing a person's weight in kilograms by the square of height in meters. For children and teens, BMI is age- and sex-specific and is often referred to as BMI-for-age. A child's weight status is determined using an age- and sexspecific percentile for BMI rather than the BMI categories used for adults. This is because children's body composition varies as they age and varies between boys and girls. Therefore, BMI levels among children and teens need to be expressed relative to other children of the same age and sex.

For example, a 10-year-old boy of average height (56 inches) who weighs 102 pounds would have a BMI of $22.9 \mathrm{~kg} / \mathrm{m}^{2}$. This would place the boy in the $95^{\text {th }}$ percentile for BMI, and he would be considered as obese. This means that the child's BMI is greater than the BMI of $95 \%$ of 10 -year-old boys in the reference population.

\section{Childhood obesity in India}

It cannot be denied that childhood obesity is on the rise.
Chew on the following statistics sourced from the Indian Journal of Endocrinology and Metabolism:

A. Somewhere between 5.74 percent and 8.82 percent of schoolchildren in India are obese.

B. In urban south India, 21.4 percent boys and 18.5 percent girls aged 13-18 are either overweight or obese.

Worldwide, in the year 2000, the International Obesity Task Force (IOTF) declared about 10 percent of children aged 5-17 (about 155 million) were overweight, out of which two to three per cent (30 to 45 million) were obese.

Among the reasons for childhood obesity were ubiquitous processed foods, fast foods, and foods that don't unfortunately love your child back as much as your child loves them. Add that to the fact outdoor activities have been replaced by digital ones, and we have a scenario where children are eating more calories than they can expend.

\section{Reducing prevalence of childhood obesity- a great} task

It is easier to move a stone than a mountain. However, the effort of relocating the mountain is worth it if the move will benefit the future generations. For example, the rise in obesity in children prompted many countries to take actions towards reducing its prevalence. However, recent analyses have indicated that these steps may not be enough to reach the target within the stipulated time. 


\section{Current Research in Diabetes \& Obesity Journal}

Member countries of the World Health Organization (WHO) have resolved to ensure that there is no increase in levels of obesity by the year 2025 , based on obesity prevalence in the year 2010. Between 2000 and 2013, the Global Burden of Disease collaborative collected data on obesity trends from 184 WHO member countries. Researchers at the World Obesity Federation, United Kingdom used this data to extrapolate the prevalence of obesity in 2025. They found that worldwide, in the next eight years, around 268 million children and adolescents between the ages of 5 and 17 years are likely to weigh on the heavier side, of which 91 million are likely to be obese. These figures take into account current governmental policies and lifestyle habits. In addition, by the year 2025, around 12 million children are likely to suffer from glucose intolerance, 4 million children could develop type 2 diabetes, 27 million children could be diagnosed with high blood pressure, and 38 million children are likely to develop liver disease.

Overweight and obese children are likely to stay obese into adulthood. Environmental factors, lifestyle preferences, and cultural environment play pivotal roles in the rising prevalence of obesity worldwide. Obese children are more likely to develop diseases like diabetes and cardiovascular diseases at a younger age. The mechanism of obesity development is not fully understood and it is believed to be a disorder with multiple causes. Obesity are assumed to be the results of an increase in caloric and fat intake. On the other hand, there are supporting evidence that steady decline in physical activity have been playing major roles in the rising rates of obesity. Evidence also indicates that dietary habits acquired in childhood persist through to adulthood and research also indicates a role for childhood eating behavior on adult health and chronic non communicable diseases. Main cause for childhood obesity includes irregular eating habits, excessive sugar intake and lack of physical activities plays major role in obesity. The rate of youngsters aged 6-11 years in the United States who were obese expanded from 7\% in 1980 to about $18 \%$ in 2012. In 2012, more than $33 \%$ of kids and youths were overweight or obese.

Nutrition Education is combination of educational strategies, accompanied by environmental support. Nutrition Education is to facilitate voluntary adoption of food choices and other food- and nutrition-related behavior conducive to health and well-being. Nutrition education provides Service to support the Child Nutrition Programs through training and technical assistance for food service, nutrition education for children and their caregivers, and school and community support for healthy eating and physical activity.

Research also shows that most of the children's eating behaviour are unsatisfactory. For example, the Heart Study in the US showed that the majority of 10 year olds exceeded the American Heart Association dietary recommendations for total fat, saturated fat and dietary cholesterol. A survey in the UK showed a similar picture, with $75 \%$ of children aged 10 -
11 exceeding the recommended target level for percentage of energy derived from fat. Comparable results have also been reported.

For children Junk food can be appealing and they do not always understand the health consequences of their eating habits. However, regularly consuming fattening junk food can be addictive for children and lead to complications like obesity, chronic illness, low self-esteem and even depression, as well as affecting how they perform in school and extracurricular activities. Prevention of childhood obesity is important to prevent chronic disease not only in childhood but also in adulthood [1].

\section{What can childhood obesity lead to?}

Consumption of sweetened beverages and the frequency of large portions of energy-dense food would increase the risk. Fast-food restaurants have a relative abundance of energy-dense food and sweetened beverages. Consumption of low-energydense food, such as fruits, salads and increased calcium intake has also been associated with a lower risk of obesity.

The presence of obesity in childhood greatly increases the risk of developing diabetes in young adulthood and heart problems in later life. Obesity also adversely affects the hormonal development of the child. Girls tend to develop earlier puberty and menarche, along with irregularities in their menstrual cycles and also develop facial hair. Boys, on the other hand, have an impaired development of their external genitalia and tend to have enlargement of their 'breast' region.

\section{Childhood obesity; health risk now and later}

Childhood obesity has increased in recent years. Most common causes are genetic factors, lack of physical activity, unhealthy eating patterns, or a combination of these factors. Although weight problems run in families, not all children with a family history of obesity will be overweight. The most important factors underlying the obesity epidemic are the current opportunities for food intake coupled with limited energy expenditure. The consequences of childhood and adolescent obesity include earlier puberty and menarche in girls, type 2 diabetes and increased incidence of the metabolic syndrome in youth and adults, and obesity in adulthood. These changes are associated with cardiovascular disease [2].

In one study, nearly one third of children and adolescents consumed fast food; they ate greater number of calories with a greater caloric density food. The researcher claimed that such food pattern would lead to an additional $57 \mathrm{kcal}$ in the daily diet of the average child and could account for $6 \mathrm{lb}$ weight gain per child per year. Consumption of sweetened beverages and the frequency or large portions of energy-dense foods would increase the risk. Fast-food restaurants have a relative abundance of energy-dense foods and sweetened beverages. Consumption of low energy dense foods and increased calcium intake had also been associated with a lower risk of obesity [3]. 


\section{Current Research in Diabetes \& Obesity Journal}

The likelihood of an obese child becoming an obese adult increases with the age of the child. Multiple studies have shown the association of pediatric and adolescent obesity with obesity in adults. Almost half of overweight adults were overweight as children [4]. Previous findings from the Bogalusa Heart Study (BHS) revealed that childhood overweight was an important determinant of cardiovascular risk factors in young adulthood [5]. Thus, prevention as well as treatment of overweight and obesity in adulthood necessitates the detection of children who are likely to become overweight as adults. It is necessary to teach children to follow healthy eating habits and teaching importance of physical exercise since childhood. Encourage healthy eating by increasing serving of fruits \& vegetables. Buy fewer soft drinks $\&$ high-fat, high-calorie snacks, making sure child eats breakfast every day. Today's healthy child is tomorrow's healthy adult!

\section{Conclusion}

Obesity is to be controlled and the government should boldly ban some of the FAST FOODS which promote obesity. Parents and teachers and peer groups have the responsibility to tackle this problem which is not so easy to solve. But, anyhow IF THERE IS A WILL THERE IS A WAY.

\section{References}

1. Barlow SE and the Expert Committee (2007) Expert committee recommendations regarding the prevention, assessment, and treatment of child and adolescent overweight and obesity: summary report. Pediatrics 120(Supplement 4): S164-S192.

2. Cote AT, Harris KC, Panagiotopoulos C, Sandor GG, Devlin AM (2013) Childhood obesity and cardiovascular dysfunction. J Am Coll Cardiol 62(15): 1309-1319.

3. Whitlock EP, Williams SB, Gold R, Smith PR, Shipman SA (2010) Screening and interventions for childhood overweight: a summary of evidence for the US Preventive services task force. Pediatrics 116(1): e125-e144.

4. Biro FM, Wien M (2010) Childhood obesity and adult morbidities. Am J Clin Nutr 91(5): 1499S-1505S.

5. Deshmukh Taskar P, Nicklas TA, Morales M, Yang SJ, Zakeri I, et al. (2006) Tracking of overweight status from childhood to young adulthood: the Bogalusa Heart Study. Eur J Clin Nutr 60(1): 48-57.

\begin{tabular}{|l|}
\hline \multicolumn{1}{|c|}{ Your next submission with Juniper Publishers } \\
will reach you the below assets \\
- Quality Editorial service \\
- Swift Peer Review \\
- Reprints availability \\
- E-prints Service \\
- Manuscript Podcast for convenient understanding \\
- Global attainment for your research \\
- Manuscript accessibility in different formats \\
( Pdf, E-pub, Full Text, Audio) \\
- Unceasing customer service \\
Track the below URL for one-step submission \\
https://juniperpublishers.com/online-submission.php \\
\hline
\end{tabular}

